\title{
Evaluation of the cervical spine, breathing mode and burnout syndrome in university students with temporomandibular disorder
}

Karen Sella de Andrade Negrão; Natali Maciel Folster; Tiago Tsunoda del Antônio, Camila Costa de Araujo, Joyce Karla Machado da Silva.

Universidade Estadual do Norte do Paraná, Jacarezinho, (PR), Brazil.

\begin{abstract}
Background: The temporomandibular joint is responsible for performing the functions of the stomatognathic system. Disorders that affect the temporomandibular joint causing changes in its functioning result in what is known as temporomandibular disorder (TMD). The etiology of TMD is complex and multifactorial, being considered a set of clinical problems that involves not only TMJ, but surrounding structures, which may be related to posture and cervical mobility, breathing and psychosocial factors. Objective: to analyze the cervical posture and mobility, breathing mode, as well as the presence of Burnout Syndrome and possible relationships with temporomandibular disorder in university students. Methods: The RDC/TMD was used to define the presence of temporomandibular disorder, the breathing mode was assessed using the "water in the mouth" test and the mirror test, flexion with rotation was tested using the Sanny® fleximeter and cervical posture was assessed using the PAS/SAPO®, Burnout Syndrome was assessed using the Maslach Burnout Inventory for students. 60 university students from the Health Sciences Center of the Universidade Estadual do Norte do Paraná, participated in the study. Results: Temporomandibular disorder was more frequent in physiotherapy students and flexion with right rotation was lower in students with temporomandibular disorder, as well as breathing mode, with mouth breathing being the most commonly found in these subjects. However, no statistically significant difference was observed between groups with and without TMD. The Burnout Syndrome obtained a higher mean of the emotional exhaustion domain, with no difference between the groups with and without TMD. Conclusion: TMD did not influence the cervical mobility and the breathing mode, and there is no indication of Burnout Syndrome in university students according to the results obtained, however, the Emotional Exhaustion domain had a higher score.

Keywords: Temporomandibular Joint; Breathing Mode; Cervical Mobility; Burnout Syndrome; Temporomandibular Disorder; Cranio-Cervical
\end{abstract}

\section{BACKGROUND}

The temporomandibular joint (TMJ) is a joint formed by several structures, being responsible for performing complex movements associated with the action of the masticatory muscles, thus being considered an element of the stomatognathic system, which is a functional unit of the organism. TMJ acts harmoniously in the performance of functional tasks, such as chewing, phoning, swallowing and breathing, for this, it is necessary that it works properly ${ }^{(1,2)}$. TMJ dysfunctions are called temporomandibular disorders (TMD), which is defined as a set of changes that cover several clinical problems involving the masticatory muscles and associated structures such as the cervical spine ${ }^{(3)}$.

More global changes also seem to be involved in the etiology of TMDs, especially body posture and, more recently, the influence of ventilatory mechanics and standards on TMDs. Temporomandibular disorder can lead to adaptations and compensations in the body's structures in an attempt to decrease the subject's pain or discomfort, leading, in most cases, to deviations in body posture including head positioning ${ }^{(4)}$. It is believed that the head posture can interfere with the jaw posture and vice versa, thus configuring a downward alteration ${ }^{(5,6)}$. In addition, the functions of speech, chewing, swallowing and breathing depend on the synergism of cervical spine movements, TMJ and the skeletal muscle system involved. In this way, the position of the head and cervical spine can directly interfere in the performance of these functions ${ }^{(7,8)}$. TMJ and the movement segments of the upper cervical spine (C1-C2) are anatomically proximal. Functionally, the opening of the mandible tends to involve the atlanto-occipital extension, while the mandible involves the opposite cranial movement ${ }^{(9)}$. A specific and widely documented manual test that assesses the rotational movement of the atlantoaxial $(\mathrm{C} 1-\mathrm{C} 2)$ joints is the Flexion- Rotation Test (FRT) ${ }^{(10,11)}$. Correct muscle action for craniofacial development depends on the normal functioning of the breathing mode, with nasal breathing being the mode related to this normality. However, if there is any factor that prevents the passage of air through the nasal cavity, breathing will have a buccal pattern, which may affect the correct functioning of the stomatognathic system, thus leading to a possible muscle and postural alteration, in addition to TMJ alterations. The relationship between breathing and TMD is mainly determined by the excessive use of accessory inspiratory muscles, which can also lead to postural changes $^{(4,12)}$.

The university population, in view of the social and professional pressures they suffer regarding the financing of studies, academic achievement and relationships with teachers and colleagues, presents itself as a population which the occurrence of anxiety and stress can severely limit psychosocial well-being and/or school performance ${ }^{(13)}$ 
According to Magri et al. ${ }^{\left({ }^{14)}\right.}$, subjects with TMD may also present stress-related disorders characterized by somatic and psychological changes such as fatigue, sleep disorders, anxiety and depression, which may be related to Bunrnout Syndrome (BS). The BS is defined as a psychosocial syndrome characterized by emotional exhaustion that most often affects subjects who, in some way, deal with other people. Emerging first as a social problem resulting from frequent emotional tension being experienced by professionals and students ${ }^{(15)}$.

Given the above, the present study aimed to analyze the posture and mobility of the cervical spine, the breathing mode, the presence of BS and its possible relations with the presence of TMD, in university students of the Physiotherapy and Dentistry courses.

\section{METHODS}

This is a cross-sectional, analytical and quantitative study, in which 60 university students from the Physiotherapy and Dentistry courses in the Universidade Estadual do Norte do Paraná (UENP), at the Health Science Center (HSC), located in the city of Jacarezinho, Paraná. The project was approved by the UENP Human Ethics Committee, with number: 3.282.850.

University students were selected to participate in the study according to the course. University students over 18 years old were included in the research, with 35 participants of the Physiotherapy course and 25 of the Dentistry course.

The evaluations were carried out during the same moment with each participant individually in a classroom. Each evaluation lasted an average of 40 minutes, in which the evaluator initially explained the research objectives to the participant and delivered the Informed Consent Form. All evaluations were performed by the same evaluator, in order to avoid possible biases.

To define the presence of TMD in university students, it was used the RDC/TMD (Diagnostic Criteria for Temporomandibular Disorders), this being a questionnaire covering questions about the patient's history and altered and/or painful clinical conditions due to TMD. For the evaluation of the displacement of the movements of the mandible during the performance of the RDC/TMD, it was used the Pachymeter Sunny®".

The respiratory evaluation included the aspect of breathing mode, which could be defined as nasal, oral or mixed. The respiratory mode, oral or nasal, was verified through two criteria: The first criterion was the application of two specific tests, the "water in the mouth test", and the "mirror test" according to Menezes et al. ${ }^{(16)}$. The second criterion was assessed through three adapted questions proposed by Abreu et al. ${ }^{(17)}$ these being: one usually snores during the night; one usually sleeps with the mouth open (drooling on the pillow) and if there is complaint of stuffy nose, daily. If at least one of the criteria changed, it was considered oral or mixed breathing. To assess the participants' cervical posture, it was used the PAS/SAPO® (Postural Assessment Software/Sistema de Avaliação Postural Ortostática). This software is used as a standard for postural assessment that generates values for the posture database. The PAS / SAPO allows the user to define their own points scoring protocol, with tragus and $\mathrm{C} 7$ being the points chosen for this assessment. The cranio-cervical angle was assessed using photographs taken in the left side view. All evaluations took place in the same place, on a white background, using a small purple polystyrene ball for specific markings. The participant was positioned 3 meters away from the camera and stood in an orthostatic position with the arms along the body and with the eyes towards the horizon during the execution of the photograph, and if the participant had long hair, it was in a ponytail.

FRT was performed with the participant in the supine position, arms along the body and with the lower limbs in flexion, in which the evaluator passively performed the total cervical flexion movement with rotation up to the limit of the subject's movement. The movements were repeated three times and the average of it was used for data analysis. For this evaluation the Fleximeter Sanny ${ }^{\circledR}$ was used, which is the equipment that excels in research to assess flexibility. During the assessment, the fleximeter was positioned at $0^{\circ}$ on the top of participant's head and secured with a tape below the participant's chin. To assess the presence of Burnout Syndrome, it was used the Maslach Burnout Inventory - Student Survey (MBI-SS). This questionnaire was validated for Portuguese language by Campos and Maroco ${ }^{(18)}$ and is composed of three dimensions, which are: emotional exhaustion, disbelief and professional effectiveness, consisting of 15 items that refer to the feeling of students in the school context. Items are evaluated by frequency, ranging from 0 (never) to 6 (every day). It is indicative of Burnout those who score high scores of Exhaustion and Disbelief and low scores in Professional Effectiveness.

Statistical analyzes were processed using the SPSS 25.0 program, the data for this study were presented on average and their respective standard deviation (SD). The normality of the data was verified using the ShapiroWilk test. For the comparison between FRT and craniocervical angulation in groups with and without temporomandibular disorder, Student's $T$ test was used for independent samples. Student's t-test for independent samples was also used to analyze Burnout Syndrome. In order to compare the FRT and the cranio-cervical angulation with the types of temporomandibular disorder (muscle, joint or mixed), the one-way ANOVA test with Bonferroni's Post-hoc was used. This test was also used to compare the cranio-cervical angle with the breathing mode (nasal, buccal or mixed). Pearson's chi-square test was used to analyze the correlation between the variables of breathing mode and temporomandibular disorder and its types. For all tests performed, a significance level of $p<0.05$ was adopted.

\section{RESULTS}

Of the 60 evaluated subjects, $45 \%(n=27)$ had TMD, $40.7 \%(n=11)$ of these was classified as mixed type. Participants in the Physiotherapy course had a higher incidence of TMD, as shown in Table 1. 
Table 1: Characterization of the study sample showing course and gender in groups with and without temporomandibular disorders (TMD) and types of TMD.

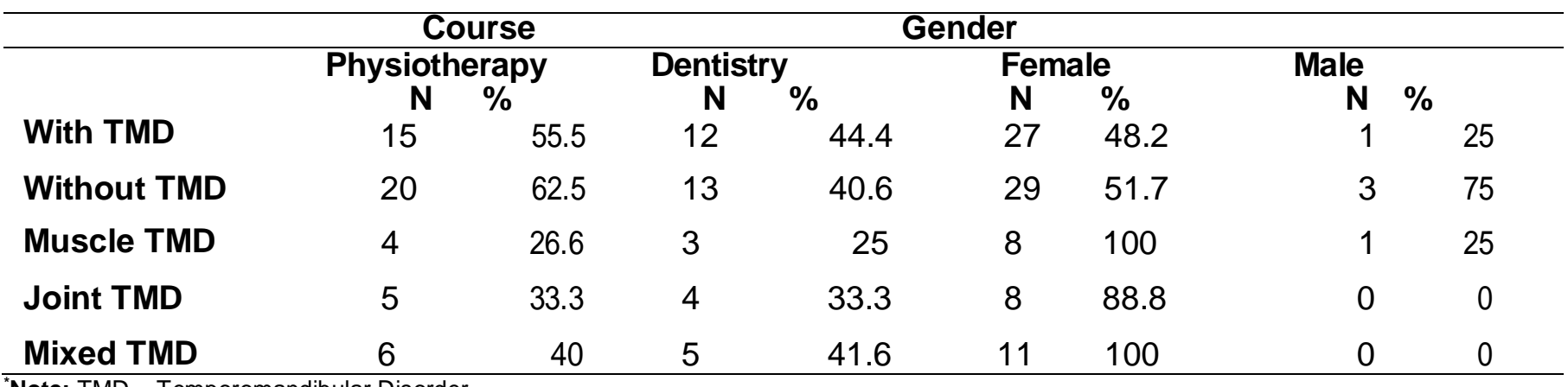

Note: TMD = Temporomandibular Disorder.

When compared to FRT in groups with and without TMD, a difference of 6.3 degrees of right FRT can be observed between groups, where in the group with TMD the amplitude of this movement was smaller when compared to the group without TMD, however, no statistically significant results were found ( $p>0.05)$.

Table 2: Comparative analysis of the FRT test in groups with and without temporomandibular disorders

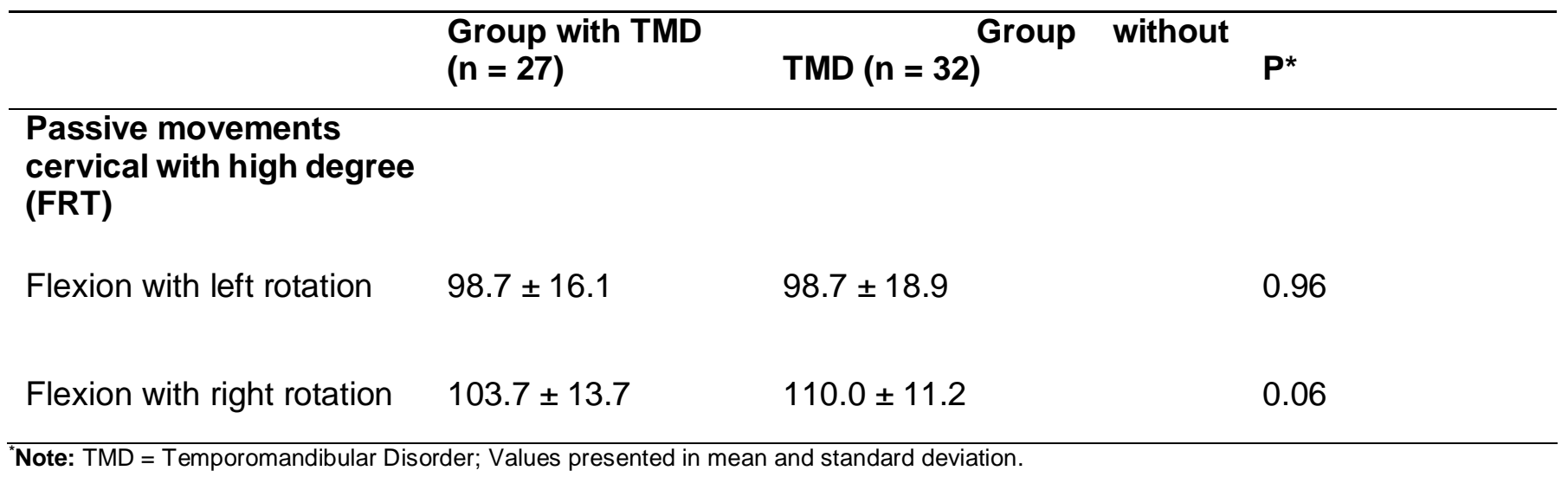

Note: TMD = Temporomandibular Disorder; Values presented in mean and standard deviation.

When comparing the breathing mode of university students with cranio-cervical angulation, it was possible to observe that, according to table 3 , there was no significance ( $p>0.05$ ). When relating cranio-cervical angulation in groups with and without TMD, there was no statistically significant difference ( $p>0.05)$, and it is possible to say that in this case the presence of TMD did not influence the cranio-cervical angulation obtained by university students.

Table 3: Comparative analysis of cranio-cervical angulation types in respiratory mode and with groups with and without temporomandibular disorders (TMD).

\begin{tabular}{llllllll}
\hline & $\begin{array}{l}\text { With TMD } \\
(\mathbf{n}=27)\end{array}$ & $\begin{array}{l}\text { Without } \\
\text { TMD } \\
(\mathbf{n}=32)\end{array}$ & $\mathbf{P}^{*}$ & $\begin{array}{l}\text { Nasal } \\
(\mathbf{n}=39)\end{array}$ & $\begin{array}{l}\text { Oral } \\
(\mathbf{n}=7)\end{array}$ & $\begin{array}{l}\text { Mixed } \\
(\mathbf{n}=14)\end{array}$ & $\mathbf{P}^{*}$ \\
\hline $\begin{array}{l}\text { Cranio- } \\
\text { cervical }\end{array}$ & $50.2 \pm 4.6$ & $48.9 \pm 4.9$ & 0.29 & $49.7 \pm 5.4$ & $48.6 \pm 4.0$ & $49.7 \pm 3.0$ & 0.87 \\
$\begin{array}{l}\text { Angulation } \\
\text { (PAS/SAPO) }\end{array}$ & & & & & & & \\
\hline
\end{tabular}

"Note: TMD = Temporomandibular Disorder; PAS/SAPO = Postural Assessment System/Sistema de Avaliação Postural Ortostática; mean and standard deviation). 
When checking the breathing mode between the groups with and without TMD and the types of TMD, no significant difference was observed ( $p>0.05)$, however, it is observed that the participants in the group with TMD had a higher frequency of oral breathing mode, as shown in figure 1.

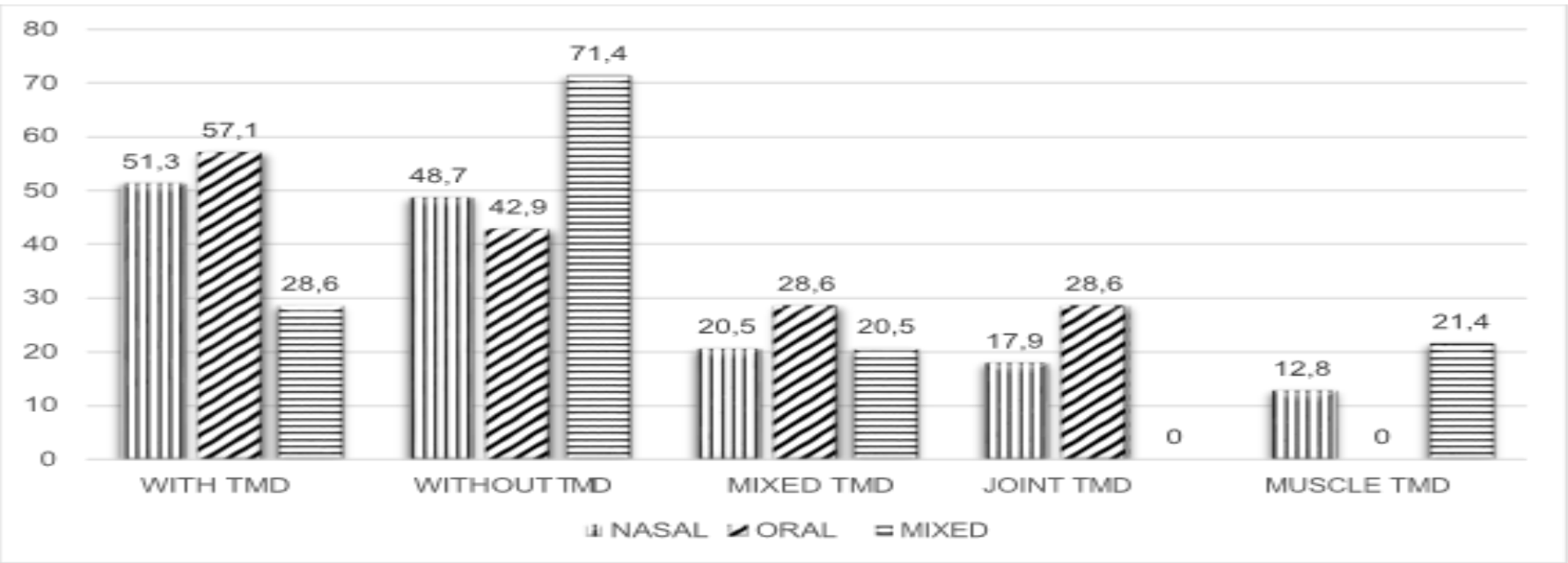

Figure 1: Frequency (\%) of breathing mode in the groups with and without TMD and the types of TMD.

When analyzing the MBI-SS domains, it can be observed that the university students evaluated were not characterized with the presence of BS, however, the average of the Emotional Exhaustion domain was the highest value obtained among the three presented in table 4 . It can also be seen in the table 4 that the areas showed no significant difference between the groups with and without TMD ( $p>0.05)$.

Table 4: Comparative analysis of MBI-SS domains between physiotherapy and dentistry courses and groups with and without temporomandibular disorders (TMD).

\begin{tabular}{|c|c|c|c|c|c|c|}
\hline Physiotherapy & $(n=35)$ & $\begin{array}{l}\text { Dentistry } \\
(n=25)\end{array}$ & $\mathbf{P}^{*}$ & $\begin{array}{l}\text { With } \\
\text { TMD } \\
(n=28)\end{array}$ & $\begin{array}{l}\text { Without } \\
\text { TMD } \\
(\mathrm{n}=32)\end{array}$ & $\mathbf{P}^{*}$ \\
\hline $\begin{array}{l}\text { MBI-SS } \\
\text { Domains } \\
\text { Emotional }\end{array}$ & & & & & & \\
\hline Exhaustion & $4.1 \pm 1.1$ & $4.3 \pm 0.9$ & 0.60 & $4.1 \pm 0.9$ & $4.2 \pm 1.1$ & 0.97 \\
\hline Disbelief & $2.1 \pm 1.5$ & $2.4 \pm 1.3$ & 0.52 & $2,3 \pm 1.4$ & $2.1 \pm 1.5$ & 0.63 \\
\hline $\begin{array}{l}\text { Professional } \\
\text { Effectiveness }\end{array}$ & $3.8 \pm 0.7$ & $3.8 \pm 1.0$ & 0.75 & $3.9 \pm 0.9$ & $3.7 \pm 0.8$ & 0.41 \\
\hline
\end{tabular}

\section{DISCUSSION}

TMD has been studied in different populations. According to Bezerra et al. ${ }^{(19)}$, health students have high levels of anxiety and stress, which are considered psychological factors involved in TMD situations. In the present study, TMD was found more frequently among undergraduate physiotherapy and female students, which corroborates with the study of Amaral ${ }^{(20)}$, when reporting that women are the most affected with TMD when compared to men. The cervical spine is linked to TMJ through the supra and infrahyoid muscles that participate in both the jaw and cervical spine mobility ${ }^{(21)}$. The right FRT of the evaluated students showed a lower angle frequency in the group with TMD compared to the group without TMD. This finding can be explained by the study sample, which showed a higher frequency of TMD on the right and on both sides when compared only to the left side, which may have been a factor limiting cervical mobility on the most affected side. Segundo Amaral ${ }^{(20)}$, the decreased mobility of the cervical spine can be explained due to the anatomical relationship of TMJ with the upper segments of the cervical spine, the occipital bone and the $\mathrm{C} 1$ and $\mathrm{C} 2$ vertebrae, with the presence of TMD being a possible restriction to the mobility of the high cervical spine. Ferreira and collaborators ${ }^{(22)}$, also point out that the upper cervical spine (C1-C2) has presented a mobility restriction in subjects with TMD, showing that 
FRT is useful to identify the mobility of this segment. In addition, the increase in masticatory muscle activity can lead to a shortening of the posterior neck muscles and a stretching of the anterior muscles, interfering with the mobility of the cervical spine ${ }^{(23)}$.

According to Pasinato et al. ${ }^{(4)}$, there is a possible relationship between respiratory pathologies and temporomandibular disorder, in addition to suggesting that nasal obstruction is the reason for changes in craniocervical posture. Concomitant to this study, Valinhas el al. ${ }^{(12)}$, point out that subjects with mouth breathing appear to have a high risk of developing postural changes and $\mathrm{TMD}$, and corroborates the findings between the breathing mode and TMD of the present study, in which the participants who presented TMD obtained a higher frequency of oral breathing mode. When related to craniocervical angulation with the presence of TMD and with the breathing mode, no significant differences were observed between them, demonstrating that the cranio-cervical angulation was not influenced by the presence of TMD and the breathing mode of the research participants. Milanesi et al. ${ }^{(24)}$, observed that the higher the anterior position of the head, the greater the severity of signs and symptoms related to jaw movements and masticatory muscles and, according to Wiest et al. ${ }^{(25)}$, the greater the cervical lordosis, the greater the severity of the temporomandibular disorder. However, these findings do not corroborate what was found, since no relationship was observed between the cranio-cervical angle and the presence of TMD in the participants. Whereas the study of Viana et al. ${ }^{5}$ that assessed cervical posture and its relationship with the most frequent signs and symptoms found in TMD, found no relationship between the craniocervical angle and the presence of TMD, corroborating the results of the present study.

Although there are studies that relate the positioning of the head with TMD, it is possible to say that there is still little scientific research showing the effect that TMD brings to the positioning of the head. The small number of samples may have been a limiting factor in identifying a possible relationship between cervical cranial angulation and the presence of TMD and the participants' breathing mode.

Burnout Syndrome (BS) is defined as a mental disorder characterized by energy depletion, lack of professional achievement and emotional distress, which affects professionals and students who are in direct contact with other people. In addition to the stress triggered by academic activity, BS can be related to temporomandibular disorder, since TMD is related to stress and anxiety $(20,26)$. Among the most evaluated courses in relation to BS, those in the health area stand out due to charges for institutional and personal parts and responsibilities related to the lives of third parties ${ }^{(27)}$.

According to the systematic review carried out by Souza ${ }^{(28)}$, the undergraduate health courses most studied in relation to $\mathrm{BS}$ are: physiotherapy, dentistry and physical education. No indications of BS were found in the university students evaluated, however, the possibility of developing BS in these subjects should not be excluded, since the highest frequency found between the domains was Emotional Exhaustion. This domain is characterized by the emotional exhaustion experienced by the academic in the day-to-day of the course, encompassing feelings of physical and mental tiredness, stress, discouragement, irritability, headache, muscle pain and changes in sleep ${ }^{(29)}$ and, according to Maslach(30), this domain is the first to appear in the development process of the syndrome. The fact that Emotional Exhaustion was more frequent corroborates with studies such as Moura et al. ${ }^{(29)}$, that through a literature review pointed to an increase in the number of academics in the "risk" range for the development of BS, since the Emotional Exhaustion domain has been showing high scores in this population.

\section{CONCLUSION}

It is concluded with the present study that the craniocervical angulation of the evaluated students was not influenced by the presence of TMD. The right FRT had a lower angle and the mouth breathing mode was the most frequent in the group with TMD when compared to the group without TMD. It was also possible to verify that the university students had no indicative of BS.

Given the above, it is necessary to carry out studies with larger samples on this subject, in order to identify the relation that the presence of TMD have on mobility and cervical posture, as well as on the breathing mode and the presence of BS in university students.

AUTHORS' CONTRIBUTIONS: KSAN: data collection, assessments, manuscript design and writing of the article; NMF: data collection and tables of the result; TTDA: data analysis; CCA: article review; JKMS: adviser, training for data collection and article editing.

FINANCIAL SUPPORT: Nothing to declare.

CONFLICT OF INTEREST: The authors declare that there was no conflict of interests.

\section{REFERENCES}

1. Taucci R, Bianchini $E$. Verificação da interferência das disfunções temporomandibulares na articulação da fala: queixas e caracterização dos movimentos mandibulares. Rev Soc Bras Fonoaudiol. 2007;12(4):274-80.

2. Saes M, Nogueira D, Silveira M, Siqueria F. Profile of the patients with temporomandibular disorder: a physiotherapeutic approach. Rev. Insp. 2013;5(1).

3. Gonzalez D, Andrade D, Gonzalez T, Martins M, Fernandes F, Corrrêa J, et al. Correlação entre disfunção temporomandibular, postura e qualidade de vida. Rev Bras Crescimento Desenvol Hum. 2008;18(1):79-86.

4. Pasinato F, Corrêa E, Peroni A. Avaliação da mecânica ventilatória em indivíduos com disfunção têmporo-mandibular e assintomáticos. Rev. bras. fisioter. 2006;10(3):285-89. 
5. Viana M, Lima E, Menezes J, Olegario N. Avaliação de sinais e sintomas da disfunção temporomandibular e sua relação com a postura cervical. Rev Odontologia UNESP. 2015;44(3):12530.

6. Ferraz AM Jr, Guimarães $P$, Rodrigues MF, Lima RHM. Avaliação da prevalência das alterações posturais em pacientes com desordem temporomandibular: uma proposta terapêutica. Rev Serv ATM. 2004;4(2):25-32.

7. Silveira M.C, Sígolo C, Quintal M, Sakano E, Tessitore A. Proposta de documentação fotográfica em motricidade oral. CEFAC. 2006;8(4):485-92.

8. Piccin CF. Postura craniocervical, disfunção temporomandibular e cervical em pacientes com apneia obstrutiva do sono. Santa Maria [Dissertação]. Santa Maria (RS): Universidade Federal de Santa Maria, Rio Grande do Sul; 2015.

9. Eriksson P, Haggman-henrikson B, Nordh E, Zafar H. Coordinated mandibular and head-neck movements during rhythmic jaw activities in man. J. Dent. Res. 2000;79(6):1378-84.

10. Mark O, Hall T, Robinson K, Blackmore, A. The diagnostic validity of cervical flexion-rotation test. Man Ther. 2007;12(3):256-62.

11. Hall T, Briff K, Hopper D, Robinson K. Comparative analysis and diagnostic accuracy of the cervical flexion-rotation test. J. Headache Pain. 2010;11(5):391-7.

12. Valinhas S. Inter-relação entre padrão facial, má oclusão, DTM, postura cervical e tipo de respiração em jovens de 12 a 15 anos. Dissertação (Mestrado Integrado em Medicina Dentária). Instituto Universitário de Ciências da Saúde. Gandra, 2016.

13. Maroco J, Miguel T. Inventário de burnout de Maslach para estudantes portugueses. Psicologia, Saúde e Doenças. 2009;10(2):227-35.

14. Magri LV, Melchior MO, Jarina L, Simonaggio FF, Betaglion C. Relationship between temporomandibular disorder symptoms signs and Burnout syndrome among dentistry students. Rev Dor. 2016;17(3):171-7.

15. Moura G, Brito M, Pinho L, Reis V, Souza L, Magalhães T. Prevalência e fatores associados a Síndrome de Burnout entre universitários: revisão de literatura. Psicologia, saúde e doenças, 2019;20(2):300-18.

16. Menezez V, Leal R, Pessoa R, Pontes R. Prevalência e fatores associados a respiração oral em escolares participantes do projeto Santo Amaro-Recife, 2005. Rev Bras Otorrinolaringologia. 2006;3(72):395-99.

17. Abreu R.R, Rocha R, Lamounier J, Guerra A. Prevalence of mouth bresthing among children. J Pediatr.2008;84(5):467.

18. Campos J, Maroco J. Adaptação transcultural Portugal-Brasil do Inventário de Burnout de Maslach para estudantes. Revista de Saúde Pública. 2012;46(5):816-24.

19. Bezerra BT, Ribeiro AI, Faria A, Farias A, Fontes L, Nascimento $S$, et al. Prevalência da disfunção temporomandibular e de diferentes níveis de ansiedade em estudantes universitários. Rev Dor. 2012;13(3):235-42.

20. Amaral F. Disfunção temporomandibular: alterações funcionais quanto à postura e flexibilidade craniocervical, atividade eletromiográfica da musculatura mastigatória, qualidade de vida e síndrome de burnout. [tese] Ponta Grossa (PR): Universidade Estadual de Ponta Grossa, 2018.

21. Costa AC. Correlação entre a severidade da disfunção temporomandibular e o grau de disfunção cervical em mulheres universitárias. Congresso de Pós-graduação UNIMEP, 2011.

22. Ferreira M; Waisberg C, Conti P, Bevilaqua-grossi D. A mobilidade da coluna cervical superior pelo flexionrotation teste em indivíduos com disfunção temporomandibular. Headache Medicine. 2016; 7(4):145-47.

23. Bricot B. Posturologia. 3 ed. São Paulo: Ícone, 2004.

24. Milanesi J, Correa E, Borin G, Souza J, Pasinato F. Atividade elétrica dos músculos cervicais e amplitude de movimento da coluna cervical em indivíduos com e sem DTM. Rev Fisioterapia e Pesquisa. 2011;18(4):317-333.

25. Wiest D, Condotti C, Sedrez J, Pivotto L, Costa L, Loss J. Severidade da disfunção temporomandibular e sua relação com a postura corporal. Rev Fisioterapia e pesquisa. 2019;26(2):178-184.

26. Assunção D, Gonçalves F, Andrade A, Gonçalves F, Rocha J. A ocorrência da Síndrome de Burnout em universitários de cursos da área da saúde de uma instituição privada na região Norte de Minas Gerais: um estudo transversal. Rev. Ciênc. Méd. Biol. 2019;18(1):15-20

27. Magri L, Melchior $M$, Jarina L, Simonaggio $F$, Bataglion C. Relationship between temporomandibular disorder symptoms signs and Burnout syndrome among dentistry students. Rev Dor.2016;17(3):171-7.

28. Souza MR, Caldas TCG, De Antoni C. Fatores de adoecimento dos estudantes da área da saúde: uma revisão sistemática. Revista Psicologia, Saúde e Debate. 2017;3(1):99-126.

29. Moura G, Brito M, Pinho L, Reis V, Souza L, Magalhães T. Prevalência e fatores associados a Síndrome de Burnout entre universitários: uma revisão de literatura. Rev. Psicologia, saúde e doenças. 2019;20(2):300-318

30. Maslach C, Schaufeli W. Historical and conceptual development of burnout. Professional burnout: Recent developments in theory and research.1993;116. 